\title{
Residency Scholarship Within Practice-based Research Networks
}

Amanda Weidner, MPH; Ryan Gilles, MD; Dean Seehusen, MD, MPH

\begin{abstract}
BACKGROUND AND OBJECTIVES: Finding scholarship opportunities is a common struggle for family medicine residency programs, especially communitybased programs. Participation in practice-based research networks (PBRNs) has been suggested as one option, but little is known about resident engagement in PBRNs. This study explores how PBRNs are currently involving family medicine residency programs and whether there are additional opportunities for engagement.
\end{abstract}

METHODS: We conducted a cross-sectional survey of 126 primary care PBRN directors regarding residency program involvement in PBRN governance and scholarly activity. We used descriptive statistics to characterize our sample and bivariate analyses to assess association between involvement of residency programs in PBRNs and PBRN characteristics.

RESULTS: Most responding PBRNs ( $\mathrm{N}=56,44.4 \%$ response rate) included at least one residency program $(80 \%)$ and many had residency faculty involved in projects $(67.3 \%)$, though involvement of residents was less common $(52.7 \%)$. When involved, residents were part of fewer projects but participated in the full range of research activities. Few PBRNs had deeper engagement with residencies such as written goals specifying their inclusion in projects $(23.6 \%)$ or residency faculty participation in the PBRN's governing body (45.5\%). Most PBRNs not currently involving residents are interested in doing so (73.9\%), and half of these have the resources to do this.

CONCLUSIONS: Most family medicine and primary care PBRNs have some involvement with residency programs, usually at the faculty level. Building on current PBRN involvement and making connections between local PBRNs and residency programs where none exist represents an excellent opportunity for education and for growing the research capacity of the discipline.

(Fam Med. 2020;52(2):91-6.)

doi: 10.22454/FamMed.2020.303653

Published Online First January 10, 2020

$\mathbf{R}$ esident and faculty scholarship are requirements for accreditation by the Accreditation Council for Graduate Medical Education (ACGME), ${ }^{1,2}$ but despite this requirement, many family medicine residency programs struggle to find enough opportunities for faculty and residents to get involved above and beyond the bare minimum of these requirements. ${ }^{3,4}$ This challenge is particularly true for community-based family medicine programs, ${ }^{5}$ which constitute the majority of family medicine residencies. To help promote scholarship for the discipline, there is a critical need to find ways to reach out to the many community-based family medicine residency programs and engage them in more scholarly opportunities.

Engagement in practice-based research, particularly through participation in practice-based research networks (PBRNs), has been suggested as an avenue to support research capacity within the field of family medicine. ${ }^{6}$ The missions of PBRNs have traditionally focused on improving the health of, and care delivery for, primary care patients and their communities. Additional emphasis has been placed on professional education and growth of the knowledge base within primary care since the Agency for Healthcare Research and Quality (AHRQ) began providing funding in $2000 .{ }^{7}$ PBRNs are a potential model for encouraging research and scholarship, particularly in community clinics, yet little is known about the way that PBRNs might play a role in engaging residency faculty and residents in research efforts. The first Council of Academic Family Medicine (CAFM) Educational Research Alliance (CERA) survey of PBRN directors found that most $(74.1 \%)$ of responding PBRNs involved fewer than five

From the Department of Family Medicine, University of Washington, Seattle, WA (Ms Weidner); Kootenai Clinic Family Medicine Coeur d'Alene Residency, Coeur d'Alene, ID (Dr Gilles); Department of Family Medicine, Augusta University, Augusta, GA (Dr Seehusen). 
residency programs. ${ }^{8} \mathrm{~A}$ more recent CERA survey of PBRN directors did note that $80 \%$ of responding PBRNs included at least one residency program, although the majority of those (61\%) included three or fewer programs. ${ }^{9}$

The regional PBRN we (authors A.W. and R.G.) work with was created following a successful pilot study combining elements of quality improvement and research within a network of residency programs, demonstrating how residencies can be successfully involved in and integral to a PBRN, ${ }^{10}$ and how involvement in a PBRN has the potential to help increase scholarship and the culture of inquiry in a program and its clinical sites out in the community. ${ }^{10,11}$ This study explores how PBRNs are currently involving residency programs and whether PBRNs may have capacity to be part of a solution to the problem of low scholarship in residency programs, particularly community-based family medicine residencies.

\section{Methods}

\section{Study Population and Data \\ Collection}

We utilized a cross-sectional survey sent by email to directors of family medicine/primary care-based PBRNs as identified on the AHRQ PBRN Registry. ${ }^{12}$ We also included selfidentified directors from the 2017 North American Primary Care Research Group's Practice-based Research Network Conference in the sample population. We sent email invitations to participate with a link to the survey using the standard CERA methodology ${ }^{13}$ including five follow-up emails to encourage nonrespondents to participate. We collected data from October to November 2017. The American Academy of Family Physicians Institutional Review Board approved the project in October 2017.

There were 130 identified PBRN directors at the time of the survey. Two had previously opted out of CERA surveys and were removed from the sample. Of the 128 surveys sent, one was ultimately undeliverable and one was filled out together by codirectors of the same PBRN who had both received the survey. The final sample size was 126 .

\section{Instrumentation}

The questions were part of a larger omnibus survey conducted by CERA. The CERA steering committee evaluated questions for consistency with the overall subject aim, readability, and existing evidence of reliability and validity. Pretesting was done on family medicine educators who were not part of the target population. We modified questions following pretesting for flow, timing, and readability. Survey questions for our study focused around PBRNs and residency program involvement in PBRN governance and scholarly activity.

\section{Analysis}

All variables were categorical and were collapsed where combined values would be more informative. We first characterized our sample using descriptive statistics. We then used $\chi^{2}$ to compare bivariate associations between variables related to involvement of residency programs in PBRNs (number of residency programs involved and whether or not PBRN has a written goal to include residency programs in projects) with PBRN characteristics and measures of faculty and resident involvement. Data were missing for one respondent per question at most $(<2 \%)$. We completed all analyses using SPSS 19.0.0.

\section{Results}

\section{PBRN Characteristics}

The overall response rate for the survey was $44.4 \%(\mathrm{~N}=56)$. Most of the PBRNs in our sample were local $(32.1 \%)$ or state based $(35.7 \%)$ and most had existed for more than 10 years (62.5\%). Respondent PBRNs tended to be large, with 50 or more practitioners $(64.8 \%)$ and 20 or more practice sites $(73.2 \%$, Table 1$)$.
Residency Program, Residency

Faculty, and Resident

Involvement With PBRNs

Although most PBRNs in our sample included at least one residency program among their members $(80.0 \%)$, and were physically located at an institution that has a residency program $(78.2 \%)$, less than a quarter of respondents said that their program had written goals specifying the inclusion of residencies in projects $(23.6 \%)$. Nearly half $(45.5 \%)$ of respondents indicated that they have residency faculty on the PBRN's governing body (board of directors, steering committee, etc), but only two PBRNs (3.6\%) include residents in this governance structure. Over the 3 years before the survey, residency faculty helped to coordinate or conduct research projects or served as a coinvestigator more often than residents. Specifically, twothirds of respondents reported that faculty were ever involved in projects, including $29.1 \%$ with faculty involved in at least half of all projects over the last 3 years. Residents were ever involved in projects for $52.7 \%$ of all respondents, though only two respondents (3.6\%) had residents involved in more than $50 \%$ of projects (Table 1).

For the PBRNs that did involve residents, when residents were involved in projects, most $(50 \%$ or more) reported that they were involved in the full range of research activities: generating the research question, study design, literature reviews, data analysis, and manuscript writing (Table 1).

PBRNs with a written goal of including residencies in projects are significantly more likely to have more residencies that are a part of their network $(P<.001)$ and vice versa $(P<.001)$. When PBRNs include residencies, more residency faculty and residents themselves engage in PBRN research. Both PBRNs with a written goal of including residencies in PBRN projects and PBRNs that include more than five residency programs are significantly more likely have both faculty $(P=.001 ; P=.019)$ 
Table 1: General PBRN Characteristics and Residency Program

\begin{tabular}{|c|c|}
\hline Characteristic & N (\%) \\
\hline PBRN Scope & 56 \\
\hline Local & $18(32.1)$ \\
\hline State & $20(35.7)$ \\
\hline Regional & $13(23.2)$ \\
\hline National & $5(8.9)$ \\
\hline Years PBRN Has Existed & 56 \\
\hline 3 years or less & $5(8.9)$ \\
\hline $4-10$ years & $16(28.6)$ \\
\hline$>10$ years & $35(62.5)$ \\
\hline Number of Active Practitioners & 54 \\
\hline Less than 20 & $9(16.7)$ \\
\hline $21-49$ & $10(18.9)$ \\
\hline$\geq 50$ & $35(64.8)$ \\
\hline Number of Practice Locations & 56 \\
\hline Less than 10 & $4(7.1)$ \\
\hline $10-19$ & $11(19.6)$ \\
\hline$\geq 20$ & $41(73.2)$ \\
\hline Number of Residencies Part of PBRN & 55 \\
\hline 0 & $11(20.0)$ \\
\hline $1-4$ & $31(56.4)$ \\
\hline 5 or more* & $13(23.6)$ \\
\hline PBRN Is Physically Located at an Institution That Has a Residency Program & 55 \\
\hline Yes & $43(78.2)$ \\
\hline No & $12(21.8)$ \\
\hline PBRN Has Written Goals to Include Residencies In Projects & 55 \\
\hline Yes & $13(23.6)$ \\
\hline No & $42(76.4)$ \\
\hline PBRN Governing Body Includes Residency Faculty & 55 \\
\hline Yes & $25(45.5)$ \\
\hline No & $27(49.1)$ \\
\hline Unsure & $3(5.5)$ \\
\hline PBRN Governing Body Includes Residents & 55 \\
\hline Yes & $2(3.6)$ \\
\hline No & $52(94.6)$ \\
\hline Unsure & $1(1.8)$ \\
\hline $\begin{array}{c}\text { Projects Over Last } 3 \text { Years That Involved a Residency Faculty Member in Helping } \\
\text { to Coordinate/Conduct Research Project or as Coinvestigator }\end{array}$ & 55 \\
\hline $0 \%$ & $14(25.5)$ \\
\hline$>0 \%-<50 \%$ & $21(38.2)$ \\
\hline $50 \%-100 \%$ & $16(29.1)$ \\
\hline Unsure & $4(7.3)$ \\
\hline
\end{tabular}

(continued on next page) 
Table 1: Continued

\begin{tabular}{|c|c|}
\hline Characteristic & $\mathbf{N}(\%)$ \\
\hline $\begin{array}{c}\text { Percent of Projects Over Last } 3 \text { Years That Involved a Resident in Helping } \\
\text { to Coordinate/Conduct Research Project or as Coinvestigator }\end{array}$ & (55) \\
\hline $0 \%$ & $23(41.8)$ \\
\hline$>0 \%-<50 \%$ & $27(49.1)$ \\
\hline $50 \%-100 \%$ & $2(3.6)$ \\
\hline Unsure & $3(5.5)$ \\
\hline Residents Involved In: & 32 \\
\hline Generating research question & $21(65.6)$ \\
\hline Study design & $16(50.0)$ \\
\hline Literature review & $21(65.6)$ \\
\hline Data analysis & $16(50.0)$ \\
\hline Manuscript writing & $19(59.4)$ \\
\hline Unsure & $4(12.5)$ \\
\hline
\end{tabular}

Overall sample response $=56 / 126(44.4 \%)$.

* Two have more than 25 residency programs in PBRN; one has 18, one has 12, the remainder are 10 or fewer.

and residents $(P=.010 ; P=.008)$ involved in their governance structure; significantly more likely to involve faculty in more than half of projects $(P=.028 ; P=.009)$; and significantly more likely to involve residents in any research projects $(P<.001$; $P=.016$; Table 2).

Interest and Capacity for Faculty and Resident Involvement Where Not Currently Involved

Among the 23 PBRNs that reported they had not involved residents in any projects over the last 3 years, about three-quarters indicated that they would be interested in involving residents in their projects. Of those interested, nearly half indicated that they had the infrastructure and resources necessary to include residents (Table 3).

\section{Discussion}

Overall, our study showed that most family medicine and primary care PBRNs have some involvement with residency programs. More respondent PBRNs $(23.6 \%)$ had a written goal related to increasing residency scholarly activity than we hypothesized ( $10 \%$ or fewer) and more were engaged with both residency faculty and residents on projects than the very limited involvement we expected. Most involvement seems to be at the faculty level, with much less direct involvement of residents. This is not surprising, given that the logistics and timelines of research projects and residency curricula, particularly in family medicine, are not well aligned.

Despite the greater depth of engagement with residency faculty than residents, we did find that in places where residents are involved in research projects with PBRNs, they appear to be involved in meaningful ways, from generating research questions to helping with study design, data analysis, and manuscript writing. Although our sample sizes were small by the time we were able to examine PBRNs not including residency programs at all, there does appear to be some capacity for resident involvement in projects in PBRNs where they are not currently involved. This is an avenue that residency programs seeking more scholarship opportunities should consider investigating. There is still much to be gained from further exploration into these PBRNs who do not currently involve residency programs. For example, what would PBRNs want from residencies to get them involved, and what would residencies want from PBRNs to be involved? For the PBRNs that indicated they would work with residencies but don't have the infrastructure themselves, what do they believe they need to include residents, and do these assumptions match the reality of what is required?

Given the nature of the survey and its methods, these results likely include some response bias, for example, the more academicallyinclined PBRNs may be more likely to respond to surveys and also more likely to involve residency programs. Additionally, as noted above, our sample sizes for some analyses were small and so results may not necessarily be applicable to a larger sample.

The distribution of PBRNs around the country and their research infrastructure provide a great opportunity for enhancing residency program scholarship for both faculty and residents. For residency programs already involved in PBRNs, there may be opportunities to become more engaged by bringing residents on for 
Table 2: Association of PBRN Characteristics Related to Residency Program Involvement and Involvement of Faculty and Residents in PBRNs and Their Research Projects

\begin{tabular}{|c|c|c|c|c|c|c|}
\hline \multirow[t]{2}{*}{ Characteristic } & \multicolumn{3}{|c|}{ Have a Written Goal } & \multicolumn{3}{|c|}{ Number of Residency Programs } \\
\hline & Yes & No & $\boldsymbol{P}$ & $<5$ & $5+$ & $\boldsymbol{P}$ \\
\hline \multicolumn{7}{|c|}{ PBRN Scope } \\
\hline Local & $2(11.1)$ & $16(88.9)$ & \multirow{4}{*}{.061} & $18(100.0)$ & $0(0.0)$ & \multirow{4}{*}{.037} \\
\hline State & $8(42.1)$ & $11(57.9)$ & & $12(63.2)$ & $7(36.8)$ & \\
\hline Regional & $1(8.3)$ & $11(91.7)$ & & $9(75.0)$ & $2(25.0)$ & \\
\hline National & $2(40.0)$ & $3(60.0)$ & & $3(60.0)$ & $2(40.0)$ & \\
\hline \multicolumn{7}{|c|}{ Years PBRN Has Existed } \\
\hline 3 years or less & $1(20.0)$ & $4(80.0)$ & \multirow{3}{*}{.866} & $4(80.0)$ & $1(20.0)$ & \multirow{3}{*}{.680} \\
\hline 4-10 years & $3(20.0)$ & $12(80.0)$ & & $12(85.7)$ & $2(14.3)$ & \\
\hline$>10$ years & $9(26.5)$ & $25(73.5)$ & & $26(74.3)$ & $9(25.7)$ & \\
\hline \multicolumn{7}{|c|}{ Number of Active Practitioners } \\
\hline Less than 20 & $3(33.3)$ & $6(66.7)$ & \multirow{3}{*}{.811} & $8(88.9)$ & $1(11.1)$ & \multirow{3}{*}{.329} \\
\hline $21-49$ & $2(25.0)$ & $6(75.0)$ & & $8(88.9)$ & $1(11.1)$ & \\
\hline$\geq 50$ & $8(22.9)$ & $27(77.1)$ & & $25(70.6)$ & $10(29.4)$ & \\
\hline \multicolumn{7}{|c|}{ Number of Practice Locations } \\
\hline Less than 10 & $0(0.0)$ & $4(100.0)$ & \multirow{3}{*}{.117} & $3(75.0)$ & $1(25.0)$ & \multirow{3}{*}{.933} \\
\hline $10-19$ & $5(45.5)$ & $6(54.5)$ & & $9(81.8)$ & $2(18.2)$ & \\
\hline$\geq 20$ & $8(20.5)$ & $31(79.5)$ & & $30(76.9)$ & $9(23.1)$ & \\
\hline \multicolumn{7}{|c|}{ Number of Residencies Part of PBRN } \\
\hline 0 & $0(0.0)$ & $11(100.0)$ & \multirow{3}{*}{$<.001$} & -- & -- & \multirow{3}{*}{ N/A } \\
\hline $1-4$ & $5(16.7)$ & $25(83.3)$ & & -- & -- & \\
\hline 5 or more* & $8(66.7)$ & $4(33.3)$ & & -- & -- & \\
\hline \multicolumn{7}{|c|}{ PBRN Is Physically Located at an Institution That Has a Residency Program } \\
\hline Yes & $11(26.2)$ & $31(73.8)$ & \multirow{2}{*}{.496} & $32(78.0)$ & $9(22.0)$ & \multirow{2}{*}{.824} \\
\hline No & $2(16.7)$ & $10(83.3)$ & & $9(75.0)$ & $3(25.0)$ & \\
\hline \multicolumn{7}{|c|}{ PBRN Has Written Goals to Include Residencies in Projects } \\
\hline Yes & -- & -- & \multirow{2}{*}{ N/A } & $5(38.5)$ & $8(61.5)$ & \multirow{2}{*}{$<.001$} \\
\hline No & -- & -- & & $36(90.0)$ & $4(10.0)$ & \\
\hline \multicolumn{7}{|c|}{ PBRN Governing Body Includes Residency Faculty } \\
\hline Yes & $11(44.0)$ & $14(56.0)$ & 001 & $15(62.5)$ & $9(37.5)$ & 010 \\
\hline No/unsure & $2(6.9)$ & $27(93.1)$ & .001 & $26(89.7)$ & $3(10.3)$ & (0) \\
\hline & PBRN Gov & ng Body Incl & Resider & & & \\
\hline Yes & $2(100.0)$ & $0(0.0)$ & 010 & $0(0.0)$ & $2(100.0)$ & مिe \\
\hline No/unsure & $11(21.2)$ & $41(78.8)$ & .010 & $41(80.4)$ & $10(19.6)$ & .000 \\
\hline Proj & $\begin{array}{l}3 \text { Years Th } \\
\text { late/Cond }\end{array}$ & $\begin{array}{l}\text { Ivolved a Re } \\
\text { Research Prc }\end{array}$ & $\begin{array}{l}\text { ncy Facu } \\
\text { or as C }\end{array}$ & $\begin{array}{l}\text { Member in He } \\
\text { estigator }\end{array}$ & & \\
\hline$<50 \%$ or unsure & $6(15.8)$ & $32(84.2)$ & ת & $33(86.8)$ & $5(13.2)$ & - \\
\hline$>50 \%$ & $7(43.8)$ & $9(56.3)$ & .020 & $8(53.3)$ & $7(46.7)$ & .005 \\
\hline Projects Over Last 3 Year & a Resident & Helping toCo & nate/Co & t Research & ect or as $\mathrm{Cc}_{\mathrm{c}}$ & tigator \\
\hline $0 \%$ or unsure & $0(0.0)$ & $25(100.0)$ & 1 & $23(92.0)$ & $2(8.0)$ & 6 \\
\hline$>0 \%$ & $13(44.8)$ & $16(55.2)$ & -001 & $18(64.3)$ & $10(35.7)$ & (1010 \\
\hline
\end{tabular}


Table 3: Interest in, and Capacity for Resident Involvement in PBRN Research Projects Among PBRNs That Have Not Had Any Resident Involvement in Coordinating/Conducting a Research Project or as a Coinvestigator in the Last 3 Years

\begin{tabular}{|c|c|c|}
\hline Characteristic & $\mathbf{N}$ & $\%$ \\
\hline Interested in Involving Residents in PBRN Projects & 23 & - \\
\hline Yes & 17 & 73.9 \\
\hline No & 6 & 26.1 \\
\hline $\begin{array}{c}\text { PBRN has Infrastructure and Resources Necessary } \\
\text { to Include Residents in Projects }\end{array}$ & 17 & - \\
\hline Yes & 8 & 47.1 \\
\hline No & 9 & 52.9 \\
\hline
\end{tabular}

parts of research projects or encouraging the inclusion of residency representatives in PBRN governance. For residency programs not currently engaged with their local PBRNs and vice versa, we encourage reaching out to one another, as the majority of PBRNs not currently involving residents expressed interest in doing so and some have resources available to help facilitate this involvement. Through these types of connections between PBRNs and family medicine residency programs, more family medicine residents can be exposed to practice-based research, helping to educate a larger number of future family medicine scholars, a longstanding goal of the specialty. ${ }^{14,15}$

ACKNOWLEDGMENTS: The authors acknowledge Ardis Davis, MSW, for her involvement in the initiation and development of this project, including the survey questions, as well as for her background on the formation of the WWAMI Practice-based Research Network.

PRESENTATIONS: A poster sharing descriptive results from this study was presented at the 2018 North American Primary Care Research Group Annual Conference and the 2018 University of Washington Department of Family Medicine Scholarship Forum.
CORRESPONDING AUTHOR: Address correspondence to Amanda Weidner, MPH, University of Washington, Box 354696, Seattle, WA 98195-4696. 206-221-4108. aweidner@uw.edu.

\section{References}

1. Accreditation Council for Graduate Medical Education. ACGME Program Requirements for Graduate Medical Education in Family Medicine. https://www.acgme. org/Portals/O/PFAssets/ProgramRequirements/120_FamilyMedicine_2019_TCC. pdf?ver=2019-06-13-074503-640. Approved revision June 9, 2019. Accessed September 26, 2019 .

2. Accreditation Council for Graduate Medical Education. Scholarly Activity Guidelines: Review Committee for Family Medicine. https:// www.acgme.org/Portals/0/PFAssets/ProgramResources/120_scholarly-activity-guidelines. pdf?ver=2017-07-17-094145-440. Published July 2017. Accessed September 26, 2019.

3. Seehusen DA, Weaver SP. Resident research in family medicine: where are we now? Fam Med. 2009;41(9):663-668.

4. Crawford P, Seehusen D. Scholarly activity in family medicine residency programs: a national survey. Fam Med. 2011;43(5):311-317.

5. Young RA, Dehaven MJ, Passmore C, Baumer JG. Research participation, protected time, and research output by family physicians in family medicine residencies. Fam Med. 2006;38(5):341-348

6. Hester CM, Jiang V, Bartlett-Esquilant G, et al. Supporting family medicine research capacity the critical role and current contributions of US family medicine organizations. Fam Med. 2019;51(2):120-128
7. Rhyne RL, Fagnan LJ. Practice-based research network (PBRN) engagement: 20+ years and counting. J Am Board Fam Med. 2018;31(6):833-839.

8. Haggerty T, Cole AM, Xiang J, Mainous AG III, Seehusen D. Family medicine-specific practicebased research network productivity and clinical and translational sciences award program affiliation. South Med J. 2017;110(4):287-292.

9. Binienda J, Neale AV, Wallace LS. Future directions for practice-based research networks (PBRNs): a CERA survey. J Am Board Fam Med. 2018;31(6):917-923.

10. Cole A, Davis A, Keppel GA, Guirguis-Blake J, Force R, Berg A, Baldwin LM. Stimulating Research Capacity in Family Medicine Residencies by Engaging Programs in Both Research and Quality Improvement. STFM Education Column. https://www.stfm.org/publicationsresearch/publications/educationcolumns/2015/ january/ Published January 2015. Accessed July 16, 2019

11. Baldwin LM, Keppel GA, Davis A, GuirguisBlake J, Force RW, Berg AO. Developing a practice-based research network by integrating quality improvement: challenges and ingredients for success. Clin Transl Sci. 2012;5(4):351355.

12. Agency for Healthcare Research and Quality. Practice-Based Research Networks PBRN Registry. https://pbrn.ahrq.gov/pbrn-registry. Accessed July 16, 2019.

13. Seehusen DA, Mainous AG III, Chessman AW. Creating a Centralized infrastructure to facilitate medical education research. Ann Fam Med. 2018;16(3):257-260

14. Bowman MA, Lucan SC, Rosenthal TC, Mainous AG III, James PA. Family medicine research in the United States from the late 1960s into the future. Fam Med. 2017;49(4):289-295.

15. deGruy FV III, Ewigman B, DeVoe JE, et al. A plan for useful and timely family medicine and primary care research. Fam Med. 2015;47(8):636-642. 